\title{
Aspectos filosóficos do virtual e as obras simbólicas no ciberespaço
}

Silvana Drumond Monteiro

Professora adjunta do Departamento de Ciência da Informação da Universidade Estadual de Londrina. Mestre em biblioteconomia pela Puccamp. Doutora em comunicação e semiótica pela PUCSP. E-mail: drumond@sercomtel.com.br

\section{Resumo}

Discute os aspectos filosóficos do virtual e relaciona-os com o ciberespaço. Assim, o virtual é capaz de explicar um novo modelo de realização das formas simbólicas, ou seja, aquela tomada no pólo do virtual onde a conjunção e... e... constituise em aliança desenhando o conhecimento sob a forma de rede e explicando a desmaterialização das obras, contra a realidade tomada no pólo da "reificação", cujo paradigma é o da materialidade. A virtualização no ciberespaço potencializa a virtualidade da linguagem produzindo formas simbólicas que são, em essência, metamórficas. O virtual opera, ainda, a desterritorialização dos signos, portanto a desmaterialização das obras, produzindo uma complexidade na representação humana, em vez de uma substituição completa das obras.

\section{Palavras-chave}

Formas simbólicas; Virtual; Ciberespaço; Representação do conhecimento.

\section{Philosophical aspects of the virtual and the symbolic work on cyberspace}

\begin{abstract}
s
The philosophical aspects of the virtual are discussed and related to the cyberspace. So, the virtual is able to explain a new model of carrying out symbolic forms, that is, that takeover in the pole of the virtual where the conjunction and $\ldots$ and ...consists of an alliance displaying knowledge under the network form and explaining the dematerialization of the works, against reality taken over in the pole of "reification", the paradigm of which is the one of materiality. Virtualization in cyberspace makes language virtuality potential, yielding symbolic forms which are essentially metamorphic. Moreover, the virtual works up the deterritorialization of the signs, including, therefore, the dematerialization of the works yielding a complexity in human representation, instead of a complete substitution of the works.
\end{abstract}

\section{Keywords}

Symbolic forms, Virtual, Cyberspace, Knowledge representation.

\section{INTRODUÇÃO}

O virtual é o principal atributo do ciberespaço e aquele que melhor o descreve. Ele dispõe o conhecimento e a informação em um espaço e estado contínuos de modificação, em função de sua plasticidade e fluidez, permitindo a interatividade e organizando o conhecimento em forma de rizoma, um novo tipo de escritura, descrita por Deleuze \& Guattari (1995, v.1), porém só visualizada e possível, ou mesmo inteligivel, a partir do hipertexto funcional.

O virtual tem importância capital na compreensão da maneira de ser dos objetos, em especial das linguagens e obras, pois explica um tipo diferente de realidade, aquela tomada no pólo da atualização ou da "reificação", ou seja, da coisa ou da materialidade, a que estamos acostumados e com a qual mantemos uma relação de intervenção, controle e organização física dos objetos e obras.

A materialidade teve papel fundamental na noção de "representação" na ciência da informação", posto que essa relação estabelece amplo espectro de compreensões e por isso mesmo abandona, em parte, a definição clássica de representação da linguagem, ou seja, aquela que define o signo como signo, no seu desvio em relação à coisa significada (poder de representação) e a existência de convenções regulando a relação do signo com a coisa.

Entretanto, toda essa lógica da linguagem e da organização do conhecimento, formulada e baseada na linguagem verbal escrita, parece entrar em crise quando se admite que há, no ciberespaço, uma desmaterialização das formas simbólicas (obras), fato este associado corretamente ao virtual, visto que o mesmo explica a "desterritorialização dos signos" e, portanto, a "desmaterialização das obras".

O artigo pretende discutir filosoficamente a questão, para explicar um novo modelo de realização das obras no ciberespaço tomada no pólo do virtual, pois essa compreensão ajudará a perceber uma mudança de paradigma das formas simbólicas no ciberespaço. 


\section{DEFINIC̣ÃO DE VIRTUAL}

Lévy (1996) escreveu sobre o virtual e seus desdobramentos filosóficos, mostrados no quadro 1 em diferentes sentidos, do mais fraco ao mais forte:

A palavra virtual, no sentido filosófico que interessa à discussão, vem do latim medieval virtualis, derivação de virtus, designando força ou potência. $\mathrm{O}$ virtual existe em potência, e não em ato, por isso tem como pólo o atual, e não o real, comumente associado ao termo.

Assim, o virtual é potência em curso de atualização, e ambos pertencem ao real. Exemplificando o virtual, Lévy (1996) lança a situação da árvore que está virtualmente presente na semente. Então, o termo "virtual" não pode se opor ao real, mas ao atual, uma vez que a virtualidade e atualidade são apenas duas maneiras de ser diferentes. Nesse contexto, o virtual não substitui o real, mas antes multiplica as oportunidades para atualizá-lo.

Ainda de acordo com o autor, o virtual "é como o complexo problemático, o nó de tendências ou de forças que acompanha uma situação, um acontecimento, um objeto ou uma entidade qualquer, e que chama um processo de resolução: a atualização.” (Lévy, 1996, p.16).

O ciberespaço parece encarnar a força virtual, em curso de atualização, mas ao mesmo tempo sem perder a sua virtualidade: o espaço de leitura atualiza-se como espaço de escrita e vice-versa. Ou então, a leitura em outras leituras e escritas transversais.

Assim como Deleuze (apud Alliez, 1996, p. 49), que diz que todo atual "rodeia-se de uma névoa de imagens virtuais”, Lévy (1996, p.43) admite um outro estágio da atualização, ou seja, a virtualização, no qual:

"Um pensamento se atualiza num texto e um texto numa leitura (numa interpretação). Ao remontar essa encosta da atualização, a passagem ao hipertexto é uma virtualização. Não para retornar ao pensamento do autor, mas para fazer do texto atual uma das figuras possíveis de um campo textual disponível, móvel, reconfigurável à vontade, e até para conectá-lo e fazê-lo entrar em composição com outros corpus hipertextuais e diversos instrumentos de auxílio à interpretação. Com isso, a hipertextualização multiplica as ocasiões de produção de sentido e permite enriquecer consideravelmente a leitura”.

A virtualização é a passagem de uma solução dada (a atualização) a outro problema, isto é, do atual ao virtual. Entretanto, não um virtual como maneira de ser (no quadro 2, a seguir), mas a virtualização como dinâmica ou processo (se no quadro a seguir estivesse representada, a virtualização partiria do atual retornando ao virtual) (ver figura 1, p. 111). 
QUADRO 2

Os quatro modos de ser e as quatro passagens

\begin{tabular}{|c|c|c|}
\hline Substância & $\begin{array}{l}\text { Latente } \\
\text { Possível (insiste) } \rightarrow \\
\text { realização }\end{array}$ & $\begin{array}{c}\text { Manifesto } \\
\text { Real (subsiste) }\end{array}$ \\
\hline Acontecimento & $\begin{array}{l}\text { Virtual (existe) } \\
\text { atualização }\end{array} \rightarrow$ & Atual (acontece) \\
\hline
\end{tabular}

Fonte: LÉVY, Pierre. O que é o virtual. São Paulo : Ed. 34, 1996. p. $138 .^{*}$

Vale observar que esse processo não é característica conferida somente aos signos (como virtualização do pensamento), mas a humanidade tem se valido da virtualização das ações, do corpo e do ambiente físico com as técnicas e a complexidade das relações sociais por meio dos contratos, para estabelecer o estado de hominização ao longo de sua existência (Lévy, 2000).

Já o oposto do real é o possível, de acordo com Deleuze (apud Alliez, 1996), em que Lévy (1996) se baseou para escrever O Virtual. Assim, o real assemelha-se ao possível, mas lhe falta a existência, enquanto o atual responde ao virtual, no quadro 2 .

O virtual é uma configuração de forças que visa a manifestar-se em uma atualização. A isso Lévy chama de solução de um problema, dado que o virtual é problemático por essência. A atualização é, portanto, um acontecimento: "Efetua-se um ato que não estava predefinido em parte alguma e que modifica, por sua vez, a configuração dinâmica na qual ele adquire uma significação" (Lévy, 1996, p. 137).

A atualização, ao inventar, ao criar uma solução para o problema, não mobiliza recursos visando a preencher uma forma, ou ainda não coloca uma forma à disposição de um mecanismo de realização. Ela cria uma informação nova, exemplificando com a ocorrência da pronúncia de uma palavra ou interpretação de um texto.

Por isso, a atualização, que une os pólos virtual e atual, é da ordem do acontecimento, da criação, ao contrário da realização (possível-real), que, sendo da ordem da substância, supre de matéria uma forma preexistente. É uma forma na qual a realização confere uma matéria mediante uma seleção entre possíveis. A realização é uma eleição ou seleção, e não uma resolução inventiva de um problema. Então, os possíveis são candidatos à realização e, portanto, não são um campo problemático

* Pierre Lévy (1996) notadamente baseou-se na filosofia de Deleuze (muitas vezes não citado) para escrever seu livro $O$ virtual, bem como em outros temas envolvendo a questão da linguagem. como no caso do virtual, pois o "envoltório de possibilidades presta-se apenas a uma realização exclusiva" (Lévy, 1996, p. 59).

Prosseguindo com o raciocínio, a força do virtual está na sua saída, uma vez que é potência, por isso é dito "existir" como modo de ser, e o atual é a manifestação dessa força, seu acontecimento, por isso é dito "acontecer", uma vez que possui a atualização como prerrogativa. Já o possível, como lhe falta a existência, pode-se dizer que ele apenas "insiste", ou as determinações para sua existência insistem, e, no real, a substância subsiste ou resiste, porque é material.

Entretanto, o possível, o real, o virtual e o atual, embora quatro modos diferentes de ser, quase sempre operam juntos nos fenômenos concretos que se pode analisar. São as misturas que se manifestam nos fenômenos de modo que os processos de possibilidade e de realização só adquirem sentido pela dialética da atualização e da virtualização. Lévy (1996) cita o exemplo de um texto em que a possibilidade e a realização constituem-se os aspectos técnicos e materiais, mas que, por sua vez, influenciam fortemente na criação de uma mensagem e na configuração de uma ecologia cognitiva*. Não coincidentemente, a paleografia chama de "material subjetivo" aquele sobre o qual se executa uma escrita ou inscrição.

Ao mesmo tempo, na produção de um texto, há a produção e criação de idéias, portanto um espaço virtual de significações que será respondido com uma atualização ou ainda com uma virtualização, e nesse sentido o meio ou espaço de inscrição pode operar a proeminência de um modo de ser ou outro.

Visualizando de outra maneira, o diagrama da figura 1, a seguir, resume os quatro modos de ser e os processos envolvidos nessa transferência.

A dialética do virtual e do atual, quando capturada pelo real, é reificada, objetivada, coisificada. Já o possível e o real, retomados pelos processos de atualização e de virtualização, tornam-se subjetivados, pois,

"O pólo do acontecimento não cessa de implicar o pólo da substância: complexificação e deslocamento dos problemas, montagem de máquinas subjetivantes, construções e circulações de objetos. É desse modo que o mundo pensa dentro de nós. Mas, em troca, o pólo da

* O conceito de ecologia cognitiva está ligado ao estudo das dimensões técnicas e coletivas da cognição, em que as tecnologias condicionam as formas de pensamento ou as temporalidades de uma sociedade (Lévy, 1993). 
substância envolve, degrada, fixa e se alimenta do pólo do acontecimento: registro, institucionalização, reificação” (Lévy, 1996, p. 142).

Esse aspecto quádruplo que envolve os fenômenos é uma evidência, por si só, para desconfiar das teorias lingüísticas dualistas para estudo das linguagens e sobretudo do conteúdo. $\mathrm{O}$ desvelar dos processos da ordem da matéria e do acontecimento nas formas simbólicas e a necessidade de compreendê-los trazem à tona a importância dessa discussão.

Deleuze (1998, p. 241) diz que o virtual é a característica da idéia. Isso quer dizer que a existência e o pensamento são produzidos a partir dele e que tal pensamento não remete à forma de identidade no conceito. Observa-se que a linguagem é a virtualização do pensamento, de modo que no virtual "a diferença e a repetição fundam o movimento de atualização, da diferenciação como criação, substituindo, assim, a identidade e a semelhança do possível”.

Portanto, distingue-se do possível, que é concebido como a imagem do real, e do real como a semelhança do possível. O real é a semelhança de um possível que foi encarnado em uma substância à semelhança de sua imagem, que $a$ priori já tem uma "forma", uma identidade no conceito (bom senso e senso comum). Assim, o real está ligado às imagens identitárias de compreensão da linguagem e do mundo.

Apesar de a linguagem ser em essência virtual, sua atualização se prende na correspondência da identidade fixa do significado ao seu significante. Na escrita, a diferenciação como criação parece não conseguir substituir a identidade e a semelhança do possível. Deleuze propõe, em toda a sua filosofia, pensar a diferença em vez de reduzi-la a uma identidade, maquinar o pensamento, por meio da linguagem, em vez de enxergálo como algo mais profundo.

FIGURA 1

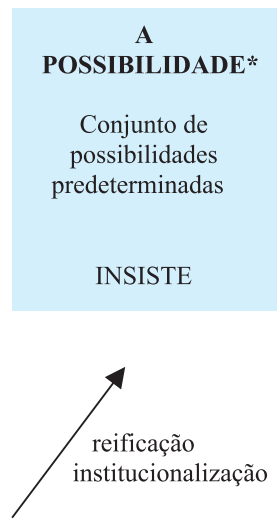

Os quatro modos de ser e os processos envolvidos

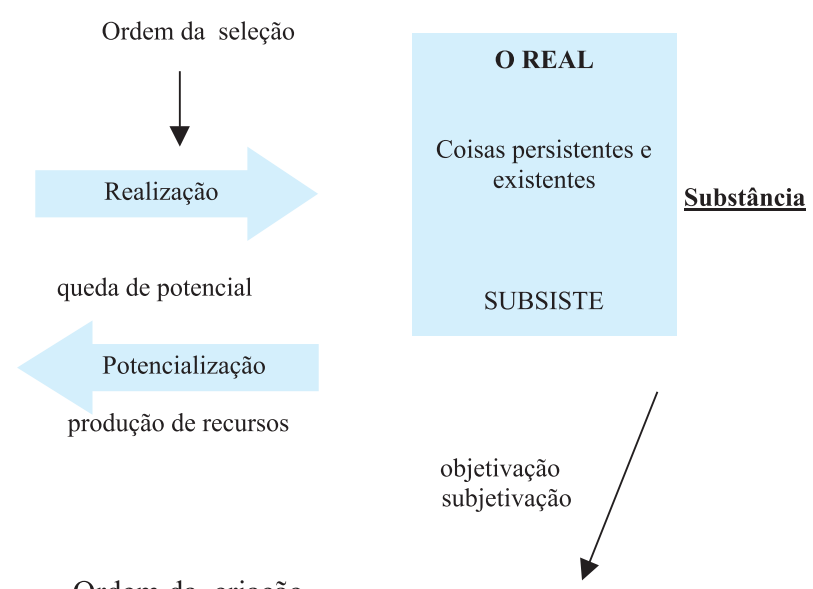

PÓLO DO MANIFESTO
PROCESSO

Ordem da criação

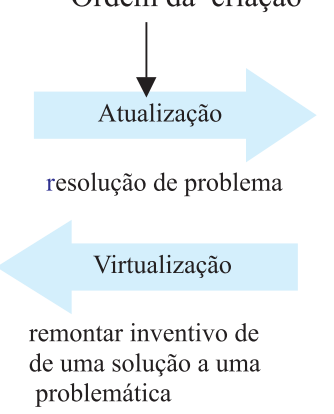

\section{O ATUAL}

Solução particular a Acontecimento um problema, aqui e agora

ACONTECE
* No primeiro quadro, o termo "potencial" foi substituído por "possibilidade", para não gerar confusão com o potencial do virtual.

Fonte: LÉVY, Pierre. O que é o virtual. São Paulo: Ed. 34, 1996. p. 145.

Se aparentemente o diagrama apresentado parece apontar um dualismo entre o acontecimento e a substância, na verdade esconde uma profunda unidade entre ambos. Assim, os fenômenos que envolvem formas concretas e simbólicas fundem-se em processos, ora da ordem da seleção, ora da ordem da criação, ora da realização, sendo o ciberespaço o ambiente que potencializa, sobretudo, os eixos inventivos da criação, dado que desloca as obras para um espaço desmaterializado onde a atualização de textos/leituras volta sempre ao estado de virtualização.

Do ponto de vista de Deleuze (apud Alliez, 1996), o objeto atual (substância) funde-se em suas imagens virtuais, em um processo chamado de atualização do virtual. Assim, entre o atual e o virtual, há trocas dentro de um circuito, de duas maneiras. 
Na primeira, ora o atual remete a virtuais como a outras coisas em vastos circuitos, onde o virtual se atualiza de forma que o objeto atual rodeia-se de círculos de imagens virtuais. Tais imagens são pouco separáveis do objeto atual e vice-versa, sendo que as imagens virtuais reagem sobre o atual, onde:

"A esses círculos mais ou menos extensos de imagens virtuais correspondem camadas mais ou menos profundas do objeto atual. Estes formam o impulso total do objeto: camadas elas mesmas virtuais, e nas quais o objeto atual se torna por sua vez virtual. O objeto e imagem são ambos aqui virtuais e constituem o plano de imanência onde se dissolve o objeto atual. Mas o atual passou assim por um processo de atualização que afeta tanto a imagem quanto o objeto" (Deleuze apud Alliez, 1996, p. 50).

Nesse primeiro circuito de atualização dos virtuais, o atual é complemento ou o produto, o objeto da atualização, que tem esta como sujeito virtual. Assim, a atualização do virtual é a singularidade, ao passo que o atual é a individualidade constituída.

No segundo momento, ora o atual remete ao virtual como seu próprio virtual, em um processo não mais de atualização, mas de cristalização, não mais de singularização, mas de individuação.

Dessa maneira, para Deleuze, a imagem virtual absorve toda a atualidade do objeto, ao passo que o objeto atual nada mais é que uma virtualidade. "O atual e o virtual coexistem, e entram num estrito circuito que nos reconduz constantemente de um a outro. Não é mais a singularização, mas uma individuação como processo, o atual e seu virtual. Não é mais uma atualização, mas uma cristalização" (Alliez, 1996, p. 54).

O objeto atual e imagem virtual, objeto tornado virtual e imagem tornada atual, e essa troca perpétua entre o virtual e o atual se define em um cristal. "É sobre o plano de imanência que aparecem os cristais" (Deleuze apud Alliez, 1996, p. 54).

Para exemplificar o segundo caso, Deleuze recorre ao filme "Dama de Xangai", no qual, como em um espelho que se apossa do personagem, tragando-o, a imagem virtual absorve toda a atualidade do personagem (Alliez, 1996). Assim, poderia ser também com o filme de Wood Allen "A Rosa Púrpura do Cairo", no qual o espectador e personagem fundem seus mundos, misturando realidade e ficção, atualidade e virtualidade.
No ciberespaço, não só o texto é em essência virtual, mas o espaço de inscrição, ou seja, a mídia torna-se também virtual. O caráter virtual do texto, no hipertexto, é elevado à potência: linguagem e meio virtualizam-se. Assim, "o texto é posto em movimento, envolvido em um fluxo, vetorizado, metamórfico, estando mais próximo do próprio movimento do pensamento, ou da imagem que hoje temos dele" (Lévy, 2000, p. 48).

Desse modo, a digitalização torna possível um imenso plano semântico, no sentido de Lévy (várias obras) ou mil platôs, no sentido de Deleuze \& Guattari (1995) acessível em todo lugar. Esse é o caráter da virtualidade do conhecimento e da informação, sempre em movimento, esperando a atualização e/ou virtualização.

Uma inferência já se pode fazer sobre as formas simbólicas do ciberespaço: são, em essência, metamórficas. Não se confinam em um fechamento físico da realização de uma forma, na fixidez temporal resultante do registro material, e sobretudo no fechamento semântico, normativo e editorial, estes dois últimos responsáveis pela normalização da forma*.

O movimento das formas está sempre produzindo novas "dobras", tanto entre os conteúdos, quanto do sentido, uma vez que não há delimitação entre a estrutura física e lógica, lembrando que a dobra é a continuidade do avesso e do direito, e o sentido se distribui dos dois lados, ao mesmo tempo. Aliás, a bidirecionalidade é a encarnação do paradoxo do sentido no ciberespaço, mas a dupla direção não diz respeito somente ao autor e leitor, mas a virtualização afeta a relação entre público e privado, próprio e comum, subjetivo e objetivo, mapa e território (Lévy, 1996).

O hipertexto, nas redes digitais, está desterritorializado**, graças aos seus dispositivos, dentre deles o "link" que faz a ligação de contexto entre os enunciados e os conteúdos, estabelece o vínculo entre os vários nós, tornando o espaço (do ciberespaço) além de contínuo, contíguo também. Evidentemente, isso provocará uma mudança nas obras de representação do conhecimento.

\footnotetext{
* Embora a padronização exista nas mídias digitais, visando à compatibilidade e conversão de dados e sistemas de informação, não se trata de maneira alguma do fechamento normativo das formas simbólicas, como no caso da normalização documentária.

** $O$ conceito de desterritorialização pode ser entendido como movimento, fluxo, aquilo que não se fixa em um território, que não perde a sua virtualidade. Teoricamente, em Deleuze \& Guattari (Mil Platôs, 5 v.) é o quarto elemento do diagrama (contra a estrutura) da linguagem, sendo o primeiro elemento a expressão, o segundo o conteúdo, e o terceiro o território.
} 


\section{O MUNDO VIRTUAL E AS OBRAS}

Embora na semiótica se use o termo "símbolo" relacionado ao signo de Peirce, isto é, ao caráter convencional e simbólico da escrita, da palavra, ou significante, não descartamos o alcance geral do conceito, ou seja, todas as formas de linguagens com seus diferentes signos e meios de inscrição, que juntamente com a escrita criam um mundo de "bens simbólicos", transversal e em conexão ao mundo dos bens materiais (até porque os símbolos e os signos, em geral, precisam encarnar na substância para existir).

Nesse contexto, há uma discussão difícil e às vezes simplista sobre a substituição das formas tradicionais do saber e da cultura em seus suportes físicos pelas formas digitais "desmaterializadas" que o mundo digital do ciberespaço tornou possível. Seguindo o pensamento de Lévy (2000) sobre essas questões, teríamos algumas considerações a fazer.

É claro que o ciberespaço irá afetar as linguagens, portanto, as obras (formas) clássicas de maneira a "complexificar", e não a "substituir" por completo o existente, assim como no urbanismo e na questão da territorialização/desterritorialização dos espaços urbanos já institucionalizados, como museus, bibliotecas, bancos, entre outros.

A questão mais séria está na "autoridade" das obras, pois, no caso da música nos formatos em MP3s e sua distribuição gratuita pelo Napster, já é possível acompanhar a discussão e as ameaças aos contratos clássicos de propriedade intelectual.

Assim como na escrita, a música como linguagem gravada suporta a réplica e precisa dela, isto é, dos exemplares para sustentar a indústria cultural e os direitos autorais. O que ameaça é a possibilidade, de fato, de o ciberespaço servir de meio para disseminar "gratuitamente" os textos, salvo o entrave jurídico do direito autoral, sem a necessidade da existência de um objeto físico do exemplar. Já a arte tradicional só faz sentido pela existência do "original" e, como portadora dessa prerrogativa, não tem como ser ameaçada pelo ciberespaço, mas o mesmo cria outras possibilidade artísticas que a inscrição digital oferece.

Nesse contexto, as obras culturais no ciberespaço irão encontrar novas "formas de expressão". A obra aberta aqui não se refere somente à possibilidade de instaurar várias interpretações, mas à possibilidade de o mundo virtual conferir múltiplos sentidos, realizações e atualizações, ao que Lévy designa "obra-fluxo", "obra-processo", ou ainda "obra-acontecimento", em que o autor "não assina uma obra acabada, mas um ambiente por essência inacabado, cabendo aos exploradores construir não apenas o sentido variável, múltiplo, inesperado, mas também a ordem de leitura e as formas sensíveis" (Lévy, 2000, p. 148).

Obviamente, essas obras refletem a nova ecologia cognitiva do ciberespaço, consolidando uma cibercultura e uma nova maneira de criar música, arte ou poesia, sendo que o declínio da figura do autor e do arquivo gravado não diz respeito à arte ou a cultura geral, mas apenas, segundo Lévy (2000), às obras diretamente ligadas à cibercultura.

Já para Deleuze \& Guattari (1997, v. 4) essa discussão remete ao conceito de "placa" de "marca" das matérias de expressão. Embora os autores se refiram à arte, o mesmo vale para as formas simbólicas que flutuam no ciberespaço, que se enquadram nas mercadorias do território e, como tal, são regidas pela lógica comercial da propriedade e, em particular, para as músicas que são distribuídas gratuitamente no KaZaA. Essa discussão remete à noção do fator $\mathrm{T}$, ou seja, do Território, onde o mesmo é primeiramente a distância crítica entre dois seres, entre as matérias de expressão, pois:

"A propriedade é primeiro artística, porque a arte é primeiramente cartaz, placa. O expressivo é primeiro em relação ao possessivo, as qualidades expressivas ou matérias de expressão são forçosamente apropriativas, e constituem em ter mais profundo que o ser [....]. Essas qualidades são assinaturas, mas a assinatura, o nome próprio, não é marca constituída de um sujeito, é a marca constituinte de um domínio, de uma morada. A assinatura não é a indicação de uma pessoa, é a formação aleatória de um domínio" (Deleuze \& Guattari, 1997, v. 4 , p. 123 , grifos dos autores).

O virtual tem total potencial para usar a Internet como repositório e repertório das formas simbólicas tradicionais, ou seja, as materializadas em suportes e aquelas que admitem a réplica, o exemplar, como os livros, jornais, revistas, CDs etc. Entretanto, essas obras são "mercadorias" do território: "Colocamos nossa assinatura num objeto como fincamos nossa bandeira na terra" [...] (Deleuze; Guattari, 1997, v. 4, p. 123), e implicam direitos autorais, propriedades, porque são, primeiro, marcas expressivas, assinaturas: "Não quero que me toquem, vou grunhir se entrarem em meu território" [...] (p.127), e ao serem transportadas para o ciberespaço, subvertem a lógica do território e criam as discussões que a legislação, elaborada para o pólo da realização, não tem conseguido acompanhar. 
É uma matéria extremamente séria, visto que os autores e artistas vêem suas obras fluírem gratuitamente, sem passar pelo crivo econômico. A Internet é regida pelo pólo do virtual, que desterritorializa completamente essas mesmas obras. É uma questão que terá de ser repensada, mas enquanto não se chega ao consenso (se for possível), os programas vão se sucedendo e se aperfeiçoando cada vez mais no acesso a todas as linguagens, impondo sua lógica.

Lévy, na obra Cibercultura (2000), prefere falar em complexificação, completude, em vez de uma substituição (completa) às noções do território. Com relação aos direitos autorais (em entrevista na Internet, Lévy, 2001) o autor defende a inteligência coletiva, a liberdade na Internet, mas admite que, em programas como o Napster, não existe uma renúncia voluntária à propriedade intelectual, como nos movimentos open source, e que a vontade dos autores não foi respeitada.

Dessa forma, relata que o direito da propriedade não deve ser simplesmente abolido, mas refinado, "tornado mais fluido e adaptado à nova situação” (2001, p. 1). Afirma também, em seu livro A inteligência coletiva (1998b), que o espaço das mercadorias é a relação com a produção e com as trocas, e o espaço do saber é a relação com o saber em toda a sua diversidade, e isso implica identidade distribuída e nômade, em oposição às identidades de pertença.

Entretanto, a solução não será fácil, porque a essência da marca territorial está em territorializar uma assinatura, ou seja, determinar funções que só são criadas e organizadas enquanto territorializadas, a exemplo dos direitos autorais, da propriedade. O livro faz parte do território, e o ciberespaço é em essência "desterritorializante" e já demonstra que cria e organiza outras funções, a despeito da lógica do território.

O conhecimento e a informação, como no caso da comunicação científica e similares, sobretudo porque não têm contratos editoriais visando ao lucro, serão o segmento que mais se beneficiará com o mundo virtual, dada a disponibilidade e facilidade de acesso.

Por enquanto, o ciberespaço vem complexificar os antigos suportes e as instituições distribuidoras, como no caso das vendas on-line de livros impressos, catálogos digitais de bibliotecas tradicionais, visitas virtuais a museus e assim por diante, sempre levando ao território ou às mercadorias do território, embora o ciberespaço sirva de reservatório de bibliotecas virtuais.

Nesse aspecto, é uma maneira de assimilar a geografia urbana tradicional no mundo digital. A crítica de Lévy
(2000, p. 188) está justamente no desafio do ciberespaço em avaliar essa assimilação territorial clássica, uma vez que existe uma diferença entre o território e o mundo virtual, pois "é a própria estrutura de comunicação midiática - um grupo central de emissores e um público de receptores passivos e dispersos - que deveria ser colocada em questão no ciberespaço”.

A idéia de assimilação desvela a impossibilidade de uma substituição completa, pois não há como trabalhar com a noção de territórios e seus domínios de propriedade decorrentes da autoridade, em um ambiente que é por essência desterritorializado.

Complexificação em vez de substituição, eis a tônica de Lévy (2000), lembrando que o cinema não acabou com o teatro, assim como a TV não acabou com o cinema, ou mesmo o livro não enterrou a fala. Entretanto, acredita-se no crescimento da cibercultura como geradora e distribuidora de bens simbólicos na sociedade.

É necessário lembrar que outros gêneros de conhecimento ou artísticos são (e serão) criados a partir da emergência das mídias, em função da configuração cognitiva tomada pelas mesmas. A tendência é a hibridização das linguagens, uma vez que o signo cresce e o homem complexifica-se ao interagir não somente com signos, mas também com tecnologias que são ao mesmo tempo intelectuais.

Já a música encontra no ciberespaço um novo nicho de transformação e simulação de sons, por meio da mixagem, remixagem e sampling, bem como um novo canal de distribuição e sobretudo divulgação de jovens músicos, subvertendo a lógica comercial das grandes gravadoras (além da polêmica discussão do Napster, e agora o KaZaA).

As imagens, de uma forma geral, perdem sua exterioridade de espetáculo para abrir-se à imersão, em que a representação é substituída pela virtualização interativa do modelo visual, de modo que a simulação sucede a semelhança.

Assim, o ciberespaço estaria complexificando as três linguagens puras da seguinte maneira (Lévy, 2000, p. 150):

- o dispositivo hiperdocumental de leitura-escrita em rede para o texto (linguagem verbal escrita);

- o processo recursivo de criação e transformação de uma memória-fluxo por uma comunidade de cooperadores diferenciados, no caso da música;

- a interação sensório-motora com um conjunto de dados que define o estado virtual da imagem. 
Quanto mais as informações se acumulam, circulam e se disseminam, melhor e maior será a ascensão do virtual, pois vimos ser essa a natureza das formas simbólicas. Ao mesmo tempo, cresce a variedade de objetos e lugares físicos com os quais estamos em contato.

Entretanto, Lévy (2000) admite que o universo informacional cresce mais rapidamente que o nosso universo de interações concretas, bastando lembrar a questão do significante fundador, em que a sociedade tem todas as regras ao mesmo tempo - jurídicas, sociais, religiosas e outras -, e existe a defasagem entre a virtualidade da língua e a realidade do conhecimento, que é experimentada, parte a parte (Deleuze, 1998).

Então, o virtual não substitui o real, ele multiplica as oportunidades para atualizá-lo. Vale lembrar que a escrita não fez com que a fala desaparecesse, ela complexificou e reorganizou o sistema de comunicação e de memória social.

Em suma, o que é do território, no território continuará. O autor e a gravação, que garantem a totalização das obras* (fechamento semântico e físico) e asseguram as condições da estabilidade do sentido, continuarão assim a funcionar, mesmo que o ciberespaço assimile as configurações arquiteturais desse território no mundo digital. Não que o ciberespaço não possa mudar esse estado de coisas, mas o território não abrirá mão de seus contratos de propriedade.

Nesses casos, a assimilação visará à divulgação do território, ou das mercadorias do território. Esse é um tipo de complexificação, no sentido mais fraco do termo, como no caso de catálogos on-line de bibliotecas, editoras e museus. Mesmo nesse sentido, temos outras maneiras de complexificação das obras que no mundo virtual repercute de forma extraordinária, pois permite a multiplicidade de linguagens no hipertexto, no qual todas as atualizações são possíveis, bem como todas as dobras de sentidos, por meio dos links, mesmo que reproduzindo e "assimilando" as antigas formas e obras citadas, porque aqui o signo cresce e ganha em semiose, pois não se trata mais de uma escrita estática e linear.

Citam-se como exemplo as bibliotecas virtuais, "The Online Books", com mais de 7 mil títulos, do acervo da

\footnotetext{
* É certo que a figura do autor é importante para instaurar o significado (autoral), conforme relata Arrojo (1992), garantindo o fechamento semântico das obras. Mas a figura do autor, a nosso ver, também está ligada à totalização da obra em si, ou seja, na questão dos direitos autorais e no fechamento físico da obra, quer seja, o autor proprietário de um pequeno território de signos, de sua marca expressiva, conforme Deleuze e Guattari (1997, v.4). Assim, a propriedade faz parte dos agenciamentos do território.
}

Universidade da Pensilvânia (http://onlinebooks. library.upenn.edu/) e o "Programa Prossiga" (www.prossiga.br), que, além dos textos eletrônicos, possui links para bibliotecas de vários países, ou ainda o "Shakespeare", site mantido pelo Instituto de Tecnologia de Massachusets, que tem a obra completa do autor, em inglês (http://the-tech..mit.edu/Shakespeare/). São exemplos de obras consideradas de domínio público ou então de cunho técnico-científico, que não esbarram na questão dos direitos autorais. Nesse aspecto, o conhecimento será o grande beneficiário desse tipo de construção, como, por exemplo, a Universidade de Phoenix, que deverá deixar de utilizar os materiais didáticos impressos em favor dos textos eletrônicos, gradualmente, a partir de 2002, mediante o pagamento de uma taxa de 70 dólares por curso (ver www.phoenix.edu/ index.html).

No sentido mais forte, seria a criação de novas formas simbólicas em que o paradigma do ciberespaço fosse usado em toda sua potência: o coletivo e a desterritorialização, como as obras fruto da cibercultura, em função das condições de simulação e produção das linguagens. Essas novas possibilidades de formas simbólicas se dão graças ao hipertexto que pode se relacionar com todas as linguagens, ao mesmo tempo, pondo em causa algumas questões ligadas às antigas obras de conhecimento e de cultura, acenando uma nova possibilidade de produção cognitiva e semiótica.

Lévy (1998a) vislumbrou uma nova representação do conhecimento possível a partir das novas tecnologias da informação, em que essas poderiam ser capazes de simular as imagens mentais. Desse modo, a linguagem imagética por meio de diagramas e simulações e também discurso narrativo poderiam representar o conhecimento científico, e as proposições do tipo argumentativo, possiveis somente no discurso dissertativo argumentativo (da escrita), passariam por uma demonstração, no sentido infográfico, e não lógico-matemático, tal como acontece com o pensamento formal, dedutivo e indutivo nas ciências*

\section{CONCLUSÃO}

Salienta-se ainda que, no sentido estritamente filosófico, toda forma simbólica, seja ela qual for, é em essência virtual. Confere à informação e ao conhecimento o caráter de virtualidade, uma vez que estes não se esgotam

\footnotetext{
* Com relação a essa nova escritura e forma de representar o conhecimento, por meio dos dispositivos digitais e virtuais, Lévy escreveu um primoroso livro intitulado A Ideografia Dinâmica (1998a), utilizando-se da semiótica, em geral, e da semiótica peirciana, em especial, para discutir as linguagens e a escrita.
} 
ou acabam quando são utilizados. Não são bens de consumo meramente materiais, seu valor e inexorabilidade vêm da virtualidade, pois a escrita carrega esses atributos, como a não-presença, o desprendimento de um aqui-e-agora, entre o contexto de produção e recepção da mensagem.

As formas simbólicas como "bens" virtuais apresentamse em problema, abrem espaço à instauração do sentido, à resolução ou atualização do texto. Entretanto, o pólo da realização é regido pela lei de exclusão mútua: ou...ou... Não há como realizar-se de duas maneiras diferentes e em dois lugares ao mesmo tempo. O impresso, ao apresentar a "obra acabada", elege uma possibilidade de realização, e a tradição hermenêutica encarrega-se de despontencializar o bem virtual do texto, uma vez que a atualização do mesmo deve atingir um denominador mental comum, ou seja, o sentido único.

Em outra palavras, retomando Deleuze (1998), embora a linguagem (mais especificamente a palavra) seja instituída de virtualidade, possuindo, portanto, um alto nível de desterritorialização, ela acaba sempre fixando o significante (isto é, a palavra). Assim, o significado não pára de deslizar-se sob a palavra, pois ela acaba operando ao mesmo tempo todo um sistema de reterritorializações. Qualquer coisa pode fazer as vezes da reterritorialização, isto é, "valer pelo território perdido; com efeito, a reterritorialização pode ser feita sobre um ser, sobre um objeto, sobre um livro, sobre o aparelho ou sistemas", ou mesmo sobre o significado, sobre o próprio significante, sendo que o regime significante faz operar todo um sistema de reterritorialização (Deleuze \& Guattari, 1997, v.5, p. 224).

No que isso implicaria? Implicaria que a virtualidade da linguagem, que tem o intuito de virtualizar o pensamento, ao ser capturada pelos registros atualizados, acaba gerando o já conhecido, tal é o problema da organização da linguagem e da atribuição da significação (porque o sentido é de outra natureza, está ligado à multiplicidade, e não à totalização semântica). Dessa maneira, o significante, para Guattari (1992) é um grande redutor da polivocidade expressiva, em que faz calar as virtualidades infinitas das línguas.

O ciberespaço proporcionará ao significante romper com as semiologias/semióticas lineares e binárias e instaurar novas linhas de fuga rizomáticas nas quais o sentido alonga-se, bifurca-se "n" vezes, nos pontos-signos de uma nova semiótica. Não mais uma coisa ou outra, mas as duas direções, várias direções, unindo signos de sentido.
O que torna o ciberespaço diferente é que o texto atualizase em um hipertexto, lembrando, sem nunca perder seu potencial virtual. $\bigcirc$ hipertexto, certamente, não se trata do mesmo texto impresso, estático, linear, preso na materialidade do objeto. Ao que parece, dada a hibridização e virtualidade, tanto das linguagens, quanto do meio, o conhecimento produz signos que geram outros signos, mas estes não se tratam, obrigatoriamente, de significantes (no sentido restrito do termo). Estamos rumo à construção da ideografia dinâmica (Lévy, 1998a), na qual novas simulações, novas representações, novos movimentos, ícones e narrativas se juntam nessa tarefa de produzir enunciados e sentido.

Ao utilizar o hipertexto, em face das características do ciberespaço, com a interatividade (ou bidirecionalidade) e a virtualidade (que põe as formas simbólicas em um espaço e estado contínuos de modificação), efetua-se a virtualização ou hipertextualização das obras.

\section{Artigo recebido em 11-03-2003 e aceito para publicação em} 24-04-2004.

\section{REFERENNCIAS}

ALLIEZ, Éric. Deleuze filosofia virtual. São Paulo : Ed. 34, 1996.

ARROJO, Rosemary. A desconstrução do logocentrismo e a origem do significado. In: _____- O signo desconstruido. Campinas : Pontes, 1992. p. $35-40$

THE BOOKS online page. Disponível em: <http:// onlinebooks.library.upenn.edu/>. Acesso em: 14 out. 2002.

DELEUZE, Gilles. Lógica do sentido. São Paulo : Perspectiva, 1998. GUATTARI, Félix. Mil platôs: capitalismo e esquizofrenia. São Paulo : Ed. 34, $1995 . \quad$ v. 1.

$$
\begin{aligned}
& \text { São Paulo: Ed. 34, 1995. v. } 2 . \\
& \text { São Paulo: Ed. 34, 1997. v. } 4 . \\
& \text { São Paulo : Ed. 34, 1997. v. } 5 .
\end{aligned}
$$

GUATTARI, Félix. Caosmose: um novo paradigma estético. São Paulo : Ed. 34, 1992.

HYLTON, Jeremy. The complete works of William Shakespeare. Operado pelo The Tech do Instituto de Tecnologia de Massachusets. Disponível em: <http://the-tech.mit.edu/Shakespeare/>. Acesso em: 20 maio 2002.

LÉVY, Pierre. Cibercultura. São Paulo : Ed. 34, 2000.

Em defesa da inteligência coletiva. Entrevistado por: Fábio Fernandes, 2001. Disponível em:<sescsp.org.br/sesc/hotsites/ pierre_levy/downloadaberto/entrevista.doc>. Acesso em: 20 ago. 2002 .

- A ideografia dinâmica: rumo a uma inteligência artificial? São Paulo : Loyola, 1998a.

A inteligência coletiva: por uma antropologia do ciberespaço. São Paulo : Loyola, 1998b .

. O que é o virtual? São Paulo : Ed. 34, 1996.

As tecnologias da inteligência: o futuro do pensamento na era da informática. São Paulo : Ed. 34, 1993.

PROSSIGA. Informação e comunicação para ciência e tecnologia. Disponível em: <http://www.prossiga.br/>. Acesso em: 4 out. 2002. UNIVERSITY OF PHOENIX. Disponível em: <http:// www.phoenix.edu/index.html>. Acesso em: 23 set. 2002. 